\title{
In vitro conservation protocol of Ceropegia bulbosa: An important medicinal and threatened plant species of Western Rajasthan
}

\author{
Suman Parihar \\ Department of Botany, Centre for advanced study, Jai Narain Vyas University, Jodhpur 342001, India
}

\section{Article history}

Received: 15 October 2016 Accepted: 12 December 2016

Published: 01 January 2017

(C) Parihar (2017)

Editor

K. K. Sabu

Publisher

Horizon e-Publishing Group

Corresponding Author

Suman Parihar

$\bigotimes_{\text {sp.bo@jnvu.edu.in }}$

\begin{abstract}
In vitro regeneration protocol has been standardized for highly medicinal and threatened succulent Ceropegia bulbosa Roxb. The paper focuses on morphogenic response of nodal explant when cultured on MS media. Murashige and Skoog medium supplemented with 6-benzyladenine (BA) $\left(2.0 \mathrm{mgl}^{-1}\right)$ was found optimum for axillary shoot bud induction with $83.4 \%$ response. Further shoots were multiplied through repetitive (3-4 times) transfer of the original explant and by subculture of the in vitro generated shoots. Maximum number of shoots $5.7 \pm 0.78$ with shoot length of $3.6 \pm 0.82$ $\mathrm{cm}$ was achieved on MS medium augmented with combination of $0.25 \mathrm{mgl}^{-1} \mathrm{BA}+0.25$ $\mathrm{mgl}^{-1} \mathrm{KN}+0.1 \mathrm{mgl}^{-1} \mathrm{IAA}$ and additives $\left(50.0 \mathrm{mgl}^{-1}\right.$ ascorbic acid, $25 \mathrm{mgl}^{-1}$ each of citric acid, arginine and adenine sulphate). For ex vitro rooting, pulse treatment of IBA 250 $\mathrm{mgl}^{-1}$ for $3 \mathrm{~min}$ was found optimum. The rooted shoots were successfully hardened in the green house condition ( $\mathrm{RH} 75-80 \%$ at $26-28^{\circ} \mathrm{C}$ ) and about $80 \%$ shoots were transferred to the garden.
\end{abstract}

\section{Keywords}

Ceropegia bulbosa; khedula; herbal medicine; ex vitro root

Parihar, S. 2017. In vitro conservation protocol of Ceropegia bulbosa: An important medicinal and threatened plant species of Western Rajasthan. Plant Science Today 4(1): 21-26. http://dx.doi.org/10.14719/pst.2017.4.1.271

\begin{abstract}
Introduction
Ceropegia bulbosa (Roxb.) commonly known as khedula, belongs to family Apocynaceae (previously known as Asclepiadaceae), and is a medicinally important plant of Thar Desert of Rajasthan. The root tubers are edible and contain cerpegin alkaloid (Mabberley, 1978). The plant tubers known for several medicinal properties and used for treatment of diarrhoea and dysentery. Tribal women used the tubers to promote fertility and vitality. C. bulbosa is measured as a good source of compounds in curing disease of kidney particularly in urinary bladder stone disease (Swarnkar and
\end{abstract}

Katewa, 2008). Khan and Pradhan (2012) reported the antiurolithic activity of Ceropegia.

Due to increased anthropozoogenic activity and livestock populations the status of wild plant predominantly those used in medicines have been affected seriously (Singh et al., 2009). Because of the pharmaceutical importance of alkaloid cerpegin and its uses as anti-ulcer, hepatoprotective, analgesic, antipyretic, hypotensive, tranquillsing and mast-cell stabilizing activity (Adibatti et al., 1991), C. bulbosa is overexploited and this plant is now considered as a threatened plant (Dhir and Shekhawat, 2014, Walter and Gillet, 1998). 
Conventionally $C$. bulbosa is propagated mainly by seeds, however, germination and viability of seeds is very poor (Goyal and Bhadauria, 2006), so it is not a competent method for the conservation of this important medicinal plant. Furthermore, the conventional methods of propagation are not able to complete the demand of pharmaceutical companies (Shekhawat et al., 2002, 2009). Consequently, there is an urgent need to establish an efficient in vitro regeneration method for the conservation of $C$. bulbosa. Plant tissue culture is a helpful method for the propagation and conservation of endangered as well as medicinally important plants (Mathur and Shekhawat, 2013, Singh et al., 2012; Thiyagarajan and Venkatachalam, 2012, Jana and Shekhawat, 2010 a,b). Some attempts have been reported on the in vitro propagation of $C$. bulbosa (Dhir and Shekhawat, 2014; Phulwaria et al., 2013). Micropropagation techniques offer the possibility of producing fair amount of identical and superior quality plants in a short stretch of time and limited space for obtaining a biomass for restoration of the species, moreover, in vitro technology is also used for production of biologically active compounds (Dhir et al., 2014; Wang et al., 2013; Dhir and Shekhawat, 2013, 2012; Jana and Shekhawat, 2012).

Cerpegin (1,1-dimethylfuro[3,4-C]pyridine$3,4(1 \mathrm{H}, 5 \mathrm{H})$-dione), the alkaloid present in root tubers of C. bulbosa (Nadkarni, 1976), was identified as pyridine, which is a rare alkaloid found in nature (Adibatti et al., 1991). Cerpegin is recognized to have analgesic properties (Sukumar et al., 1996). The aqueous extract of edible $C$. bulbosa contains polyphenols, potassium, steriods, and sugars. Plant contain greater amount of antioxidants which belong to phenolic compounds (flavonoids and phenolic acids), nitrogen-bearing compounds (amines, cyanogenic glycosides, alkaloids and non-protein amino acids), ascorbic acid and carotenoids (Dhir and shekhawat, 2014).

The aim of the present research was to develop a micropropagation protocol for Ceropegia bulbosa using nodal explant.

\section{Material and methods}

\section{Plant Material and Disinfection}

Plants of Ceropegia bulbosa were procured from Jaisalmer and Barmer district of Rajasthan (India) during rainy season and maintained in the green house of the plant biotechnology unit, Botany Department, Jai Narain Vyas University, Jodhpur. The fresh shoot sprouts were used as explant. The shoots were cut into $4-5 \mathrm{~cm}$ long segments (each with 2-3 nodes) and were prior treated with $0.1 \%(\mathrm{w} / \mathrm{v})$ Bavistin for 9-10 min, followed by 6-7 times washing with sterile water and subsequently surface sterilized with $0.1 \%$ (w/v) $\mathrm{HgCl}_{2}$ for 1-2 min. Shoot segments were washed with at least five to six changes of autoclaved distilled water under aseptic environment in laminar air flow bench so that no traces of sterilant leftover.

\section{Basal Medium and culture conditions}

MS medium supplemented with $0.8 \% \mathrm{w} / \mathrm{v}$ agar and $3 \% \mathrm{w} / \mathrm{v}$ sucrose was used as a basal medium. Prior to autoclaving the medium, $\mathrm{pH}$ was adjusted at 5.8. Test tubes with $15 \mathrm{ml}$ and conical flasks with $50 \mathrm{ml}$ of medium were capped using non absorbent cotton plugs. The medium was autoclaved at $121^{\circ} \mathrm{C}$ and $1.06 \mathrm{~kg} \mathrm{~cm}^{-2}$ for $15 \mathrm{~min}$. All cultures were incubated at $26 \pm 2^{\circ} \mathrm{C}, 16 \mathrm{~h} \mathrm{~d}^{-1}$ photoperiod at irradiance of $40-50 \mu \mathrm{mol} \mathrm{m}^{-2} \mathrm{~s}^{-1}$ PFD and 60-70\% RH.

\section{Shoot induction}

Nodal shoot segments of C. bulbosa were inoculated singly on MS medium (Murashige and Skoog, 1962) containing $0.8 \%$ agar, 3\% sucrose and different concentrations of BA (6-benzyl aminopurine) and $\mathrm{KN}$ (Kinetin) $\left(0.5-2.0 \mathrm{mgl}^{-1}\right)$. Medium was also enriched with additives namely ascorbic acid $\left(50 \mathrm{mgl}^{-1}\right)$ and $25 \mathrm{mgl}^{-1}$ each of citric acid, adenine sulphate and l-arginine.

\section{Shoot multiplication}

The cultures were multiplied by two different approaches, (1) the mother explants (after removing the newly formed microshoots) were transferred to fresh nutrient medium containing $1.0 \mathrm{mgl}^{-1} \mathrm{BA}$ and $0.1 \mathrm{mgl}^{-1}$ IAA for three passages and (2) subculturing of shoots differentiated in vitro during repeated transfer. The culture medium used for multiplication was augmented with $0.25-1.0 \mathrm{mgl}^{-1}$ of BA, $0.25 \mathrm{mgl}^{-1}$ of $\mathrm{KN}$ and 0.1 $\mathrm{mgl}^{-1}$ of IAA. Data of shoot number and shoot length as well as frequency of explants producing shoot were recorded after every 4 weeks of culture.

\section{Ex vitro rooting of in vitro raised shoots}

In vitro regenerated shoots were rooted by ex vitro method. The newly generated shoots were first taken out from culture vessel and separated, washed gently with sterile water to remove adhered agar and their bases were treated with different concentrations of IBA, NAA and NOA (100-500 $\mathrm{mgl}^{-1}$ ) for different time intervals. Shoots pulse treated with root inducing auxin were inoculated in polycarbonate capped bottles containing sterile soilrite (supplied by Kel Perlite, Bangalore, India) and is a mixture of Irish peat moss with horticulture grade perlite and exfoliated vermiculite) moistened with small amount of one-fourth strength of MS salts solution for ex vitro root induction. The bottles were kept in the green house for rooting near pad section (RH 75$80 \%$ at $26-28^{\circ} \mathrm{C}$ ) in green house. 
Table 1. Effect of different plant growth regulators and their concentrations on bud breaking from nodal shoot segment of $C$. bulbosa

\begin{tabular}{lllll}
\hline $\begin{array}{l}\text { Conc. of } \\
\text { BA }\left(\mathbf{m g l}^{-1}\right)\end{array}$ & $\begin{array}{l}\text { Conc. of } \\
\left.\mathbf{K N}_{(\mathbf{m g l}} \mathbf{1}^{\mathbf{1}}\right)\end{array}$ & Response (\%) & $\begin{array}{l}\text { Shoot number } \\
\text { Mean } \pm \mathbf{S D}\end{array}$ & $\begin{array}{l}\text { Shoot length (cm) } \\
\text { Mean } \pm \text { SD }\end{array}$ \\
\hline Control & - & - & - & - \\
0.5 & - & 39.6 & $1.1 \pm 0.22$ & $0.72 \pm 0.17$ \\
1.0 & - & 46.2 & $1.2 \pm 0.26$ & $1.5 \pm 0.32$ \\
1.5 & - & 55.8 & $1.6 \pm 0.29$ & $2.1 \pm 0.59$ \\
2.0 & - & 83.4 & $2.4 \pm 0.55$ & $2.6 \pm 0.73$ \\
& 0.5 & 00.0 & $0.0 \pm 0.0$ & $0.0 \pm 0.0$ \\
& 1.0 & 42.5 & $1.0 \pm 0.22$ & $1.5 \pm 0.26$ \\
& 1.5 & 51.4 & $1.7 \pm 0.29$ & $1.8 \pm 0.37$ \\
& 2.0 & 54.9 & $2.1 \pm 0.42$ & $1.6 \pm 0.30$ \\
\hline
\end{tabular}
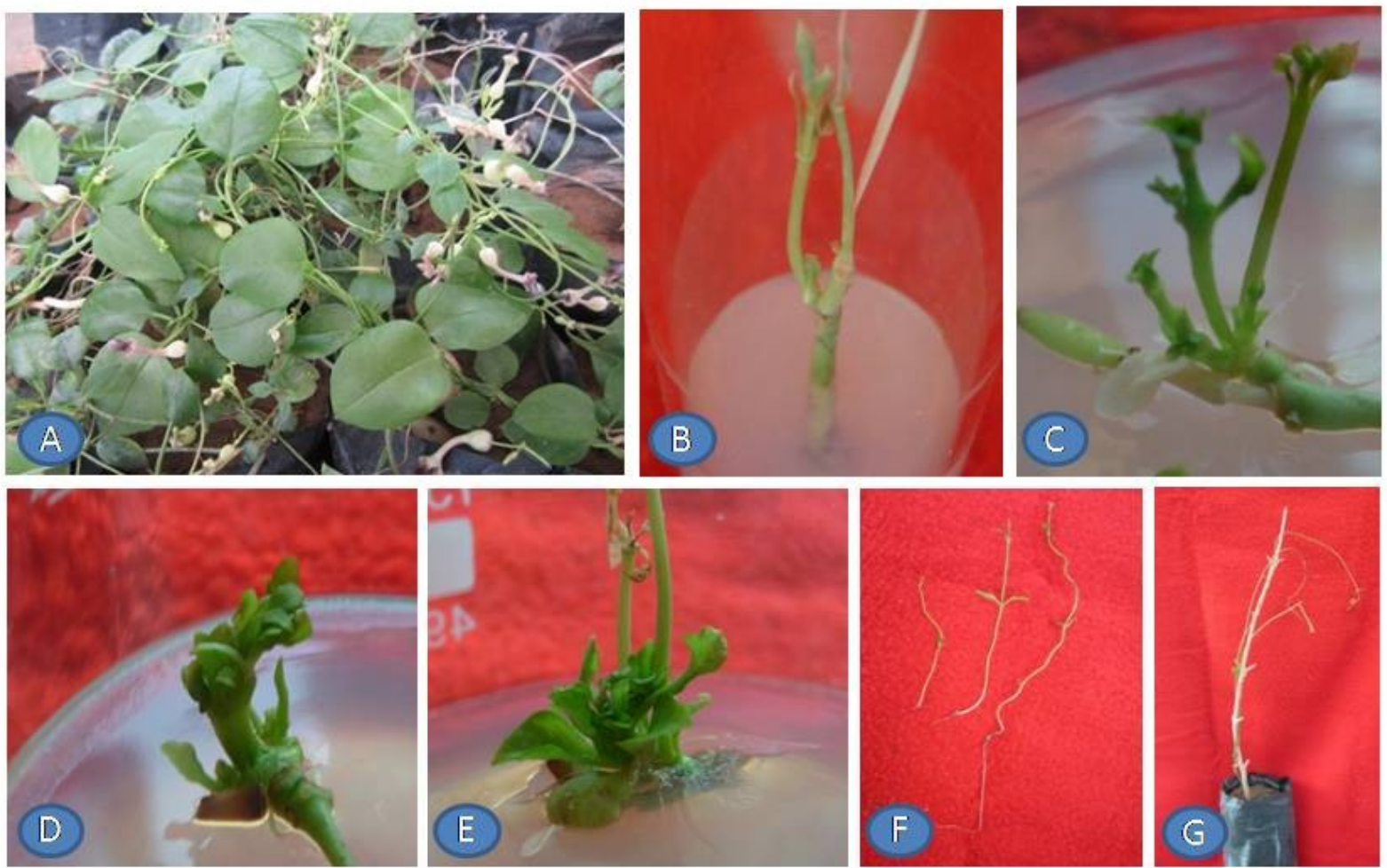

Figure 1. Shoot bud induction, multiple shoot production and rooting protocols for Ceropegia bulbosa. (A): C. bulbosa grown in green house condition, (B): Bud breaking from nodal segments on MS medium containing BAP (2.0 $\left.\mathrm{mgl}^{-1}\right)$ after 2 weeks, (C-E): Multiple shoot induction on MS medium containing BAP $\left(0.25 \mathrm{mgl}^{-1}\right)+\mathrm{kinetin}\left(0.25 \mathrm{mgl}^{-1}\right)$

+ IAA (0.1 $\left.\mathrm{mgl}^{-1}\right)$, (F): Ex vitro rooted shoots pre-treated with IBA (100 mgl-1) for 3-4 min., (G): Successfully hardened plants of C. bulbosa.

\section{Acclimatization of regenerated plantlets}

The rooted plantlets were hardened in the green house by regular loosening the caps of bottle containing plantlets after 8-10 days of root induction. After that caps were removed completely, allowing the plants to face the green house conditions for 20-25 days. The bottles were subsequently transferred from pad section of the greenhouse having high relative humidity (75$80 \%)$ and low temperature $\left(26-28^{\circ} \mathrm{C}\right)$ towards the fan section where relative humidity was comparatively low (50-60\%) and temperature was high $\left(32 \pm 2^{\circ} \mathrm{C}\right)$ for further acclimatization. After $4-5$ weeks, ex vitro rooted plantlets were transferred to polybags filled with sand, garden soil and organic manure (1:1:1). After 7-8 weeks under the greenhouse conditions, plantlets were shifted to the earthen pot containing field soil. For acclimatization experiments, 20 replicates were taken for each treatment and experiments were performed three times. These pots were transferred and maintained in nursery. 
Table 2. Effect of different plant growth regulators and their concentrations on shoot multiplication of $C$. bulbosa

\begin{tabular}{lllll}
\hline $\begin{array}{l}\text { Conc. of } \\
\text { BA }\left(\mathbf{m g l}^{-1}\right)\end{array}$ & $\begin{array}{l}\text { Conc. of } \\
\mathbf{K N}\left(\mathbf{m g l}^{-1}\right)\end{array}$ & $\begin{array}{l}\text { Conc. of } \\
\text { IAA }\left(\mathbf{m g l}^{-1}\right)\end{array}$ & $\begin{array}{l}\text { Shoot number } \\
\text { Mean } \pm \mathbf{S D}\end{array}$ & $\begin{array}{l}\text { Shoot length (cm) } \\
\text { Mean } \pm \text { SD }\end{array}$ \\
\hline Control & & & $0.0 \pm 0.0$ & $0.0 \pm 0.0$ \\
0.25 & - & 0.1 & $2.7 \pm 0.32$ & $0.95 \pm 0.29$ \\
0.5 & - & 0.1 & $2.9 \pm 0.56$ & $1.6 \pm 0.39$ \\
1.0 & - & 0.1 & $3.2 \pm 0.62$ & $2.0 \pm 0.45$ \\
0.25 & 0.25 & 0.1 & $5.7 \pm 0.78$ & $3.6 \pm 0.82$ \\
0.5 & 0.25 & 0.1 & $4.3 \pm 0.68$ & $2.1 \pm 0.46$ \\
1.0 & 0.25 & 0.1 & $3.4 \pm 0.66$ & $1.2 \pm 0.33$ \\
\hline
\end{tabular}

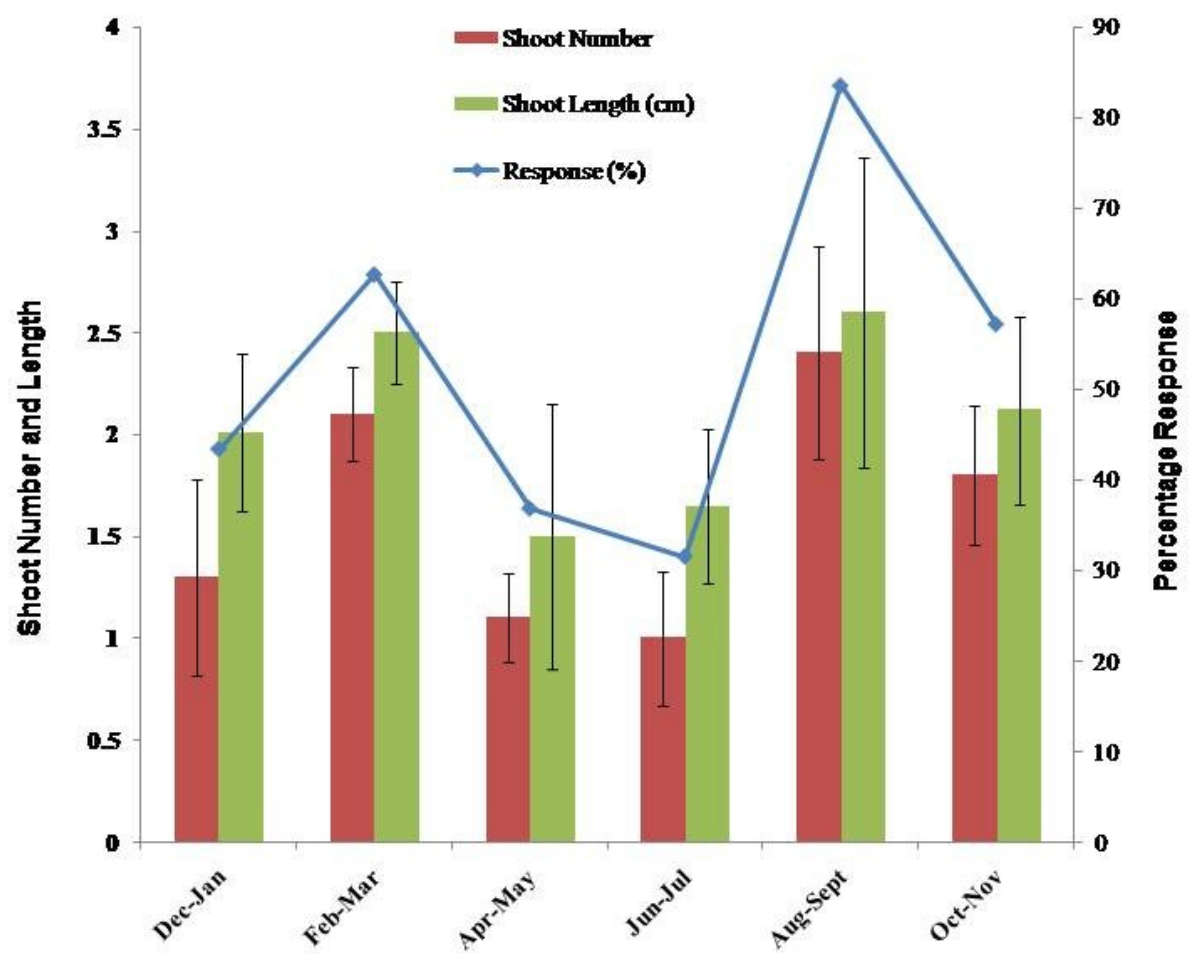

Season of Explant Collection

Figure 2. Effect of different collection seasons on percent response, number and length of shoots of Ceropegia bulbosa

Experimental design, data collection and statistical analysis

All the experiments were performed according to completely randomised block design (RBD) for single factor experiments (Compton and Mize, 1999), with a minimum of 20 replicates per treatment and were repeated thrice. The results are expressed as mean \pm SD of three experiments. Observations were noted after 4 weeks of interval.

\section{Results and discussion}

\section{Surface sterilization and culture establishment}

The nodal shoot segments collected during rainy season (August-September) was found to be the best for initiation of culture (Fig. 2). Bud breaking was observed after 10-12 days of explant inoculation on MS medium augmented with different concentrations of cytokinins.

MS medium augmented with $2.0 \mathrm{mgl}^{-1} \mathrm{BA}$ was found optimum for bud breaking and from each node, 2-3 shoots were regenerated on this medium (Fig. 1B). The frequency of the shoot regeneration was comparatively low on MS medium supplemented with KN (Table 1).

\section{Multiplication of shoots}

After the in vitro raised shoots were excised from the mother explants and cultured on the fresh medium, the shoot number increased considerably up to the third repeated transfers which reduced thereafter (Fig. 3). The maximum response was observed during the third subculture. Repeated transfer of the mother explants help in increasing the shoot number may be because of suppression 
Table 3. Effect of different concentrations of root inducing auxins on ex vitro rooting of shoots of $C$. bulbosa

\begin{tabular}{llllll}
\hline $\begin{array}{l}\text { Concentration } \\
\text { of IBA }\left(\mathbf{m g l}^{-1}\right)\end{array}$ & $\begin{array}{l}\text { Concentration } \\
\text { of NAA }\left(\mathbf{m g l}^{-1}\right)\end{array}$ & $\begin{array}{l}\text { Concentration } \\
\text { of NOA }\left(\mathbf{m g l}^{-1}\right)\end{array}$ & $\begin{array}{l}\text { Response (\%) } \\
\text { Root number } \\
\text { Mean } \pm \text { SD }\end{array}$ & $\begin{array}{l}\text { Root length (cm) } \\
\text { Mean } \pm \text { SD }\end{array}$ \\
\hline 100 & & & 52.4 & $2.0 \pm 0.28$ & $0.87 \pm 0.13$ \\
250 & & 73.5 & $3.1 \pm 0.56$ & $2.3 \pm 0.44$ \\
500 & & 41.7 & $2.2 \pm 0.45$ & $2.0 \pm 0.34$ \\
& 100 & & 54.5 & $1.4 \pm 0.32$ & $1.4 \pm 0.20$ \\
& 250 & 52.8 & $2.0 \pm 0.41$ & $1.7 \pm 0.25$ \\
& 500 & & 26.4 & $1.8 \pm 0.37$ & $1.3 \pm 0.19$ \\
& 100 & 46.8 & $1.3 \pm 0.17$ & $0.9 \pm 0.14$ \\
& 250 & 32.6 & $1.7 \pm 0.38$ & $1.1 \pm 0.16$ \\
\hline
\end{tabular}

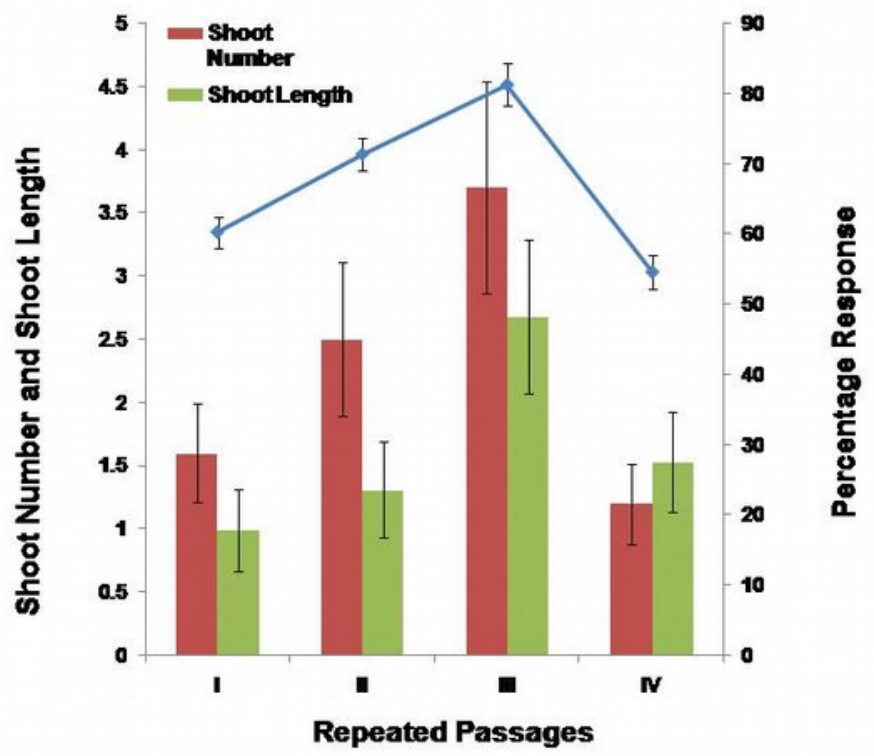

Figure 3. Effect of repeated subculture of mother explant on percent response, number and length of shoots of Ceropegia bulbosa

of apical dominance during subculture that induced basal meristematic cells to form new shoots (Shekhawat and Shekhawat, 2011).

In another approach of shoot multiplication, amplified shoots were achieved by subculturing of in vitro produced shoots (separated from mother explant) on fresh culture medium. The maximum number $(5.7 \pm 0.78)$ of shoots was produced on MS medium containing a combination of BA $\left(0.25 \mathrm{mgl}^{-1}\right)$, $\mathrm{KN}\left(0.25 \mathrm{mgl}^{-1}\right)$ and IAA $\left(0.1 \mathrm{mgl}^{-1}\right)$ with average shoot length of $3.6 \pm 0.82 \mathrm{~cm}$, within $25-30$ days (Fig. 1C-E) (Table 2).

\section{Ex vitro rooting and hardening of in vitro cloned shoots}

In order to minimize the cost and time, experiments were designed to achieve ex vitro rooting. In vitro produced shoots were harvested and washed with water to remove adhered agar to avoid bacterial and fungal contamination. The basal part of these shoots was treated with different concentrations of IBA, NAA and NOA for 3-4 min and subsequently transfers to bottles containing soilrite and placed near pad section of the green house. The maximum frequency $(73.5 \%)$ of root induction with $3.1 \pm 0.56$ roots with root length of $2.3 \pm 0.44 \mathrm{~cm}$. was recorded when the shoots were treated with $250 \mathrm{mgl}^{-1}$ of IBA for $3 \mathrm{~min}$ (Fig. 1F; Table 3). It is well established for various plant species that IBA is more efficient for inducing roots under ex vitro conditions (Patel et al., 2014; Phulwaria et al., 2013).

\section{Acclimatization and pot transfer}

The shoots regenerated under in vitro conditions could be successfully rooted ex vitro and hardened in the green house. $80 \%$ plantlets were hardened after 30-40 days of rooting. Ex vitro rooting help the in vitro raised plant in acclimatization because they have lateral root system and high root number/length, which increase percentage transplant survival rate (Yan et al., 2010). There are many reports on ex vitro rooting suggesting that, ex vitro rooted plants showed better survival in natural environmental conditions (Shekhawat et al., 2012; 
Phulwaria et al., 2013b). The acclimatized plantlets were transferred to earthen pots containing sand, garden soil, and organic manure and after a month plants were transferred to nursery and exposed to natural conditions (Fig. 1G).

\section{Conclusion}

In vitro propagation protocol of Ceropegia bulbosa has been successfully standardized and a combination of BA with $\mathrm{KN}$ and IAA was found optimum for multiple shoot induction. The process described in the study could be employed for large scale multiplication, propagation and conservation of germplasm of this important medicinal and threatened plant species.

\section{Competing Interest}

The authors declare that they have no competing interests.

\section{Acknowledgements}

Author is highly thankful to Dr. G.S. Shekhawat, Associate Professor, Department of Botany, JNV University, Jodhpur for critical comments and suggestions during the preparation of the manuscript.

\section{References}

Adibatti, N. A., P. Thirugnanasambantham, C. Kulothungan, S. Viswanathan, L. Kameswaran, K. Balakrishna, and E. Sukumar. 1991. A Pyridine alkaloid from Ceropegia juncea. Phytochemistry 30: 2449-24501. doi: 10.1016/00319422(91)83683-C

Compton, M.E, and C.W Mize. 1999. Statistical considerations for in vitro research. I.Birth of an idea to collecting data. In Vitro Cell. Dev. Biol. Plant. 35, 115-121. doi: 10.1007/s11627-999-0020-2

Dhir, R., and G.vS. Shekhawat, 2014. Ecorehabilitation and biochemical studies of Ceropegia bulbosa Roxb.: a threatened medicinal succulent. Acta Physiol Plant. 36 (6): 1335-1343. doi: 10.1007/s11738-014-1512-1

Dhir, R., Shekhawat, G. S. and A. Alam. 2014. Improved Protocol for Somatic Embryogenesis and Calcium Alginate Encapsulation in Anethum graveolens L.: A Medicinal Herb. Applied Biochemistry and Biotechnology 39: 540-549 doi: 10.1007/s12010-014-1032-x

Dhir, R., and G. S. Shekhawat. 2013. Production, storability and morphogenic response of alginate encapsulated axillary meristems and genetic fidelity evaluation of in vitro regenerated Ceropegia bulbosa: a pharmaceutically important threatened plant species. Ind Crops Prod. 47: 139-144. doi: 10.1016/j.indcrop.2013.02.005

Dhir, R., and G. S. Shekhawat. 2012. Critical review on Tecomella undulata: a medicinally potent endangered plant species of Indian Thar Deseart. Int JCurr Res. 4(6) :36-44

Goyal, D., and S. Bhadauria. 2006. In vitro propagation of Ceropegia bulbosa using nodal segments. Indian Journal of Biotechnology.243(5): 565-567.

Jana, S. and G. S. Shekhawat. 2012. RAPD analysis, antioxidant study during cell differentiation and standardization of in vitro regeneration protocol of Anethum graveolens: A medicinal herb and spice. Biologia plantarum 56(1): 9-14. doi: 10.1007/s10535-012-0009-2

Jana, S. and G. S. Shekhawat. 2010. Phytochemical analysis and antibacterial screening of in vivo and in vitro extracts of Indian medicinal herb: Anethum graveolens. Research journal of medicinal Plant 4(4): 206-212. doi: 10.3923/rjmp.2010.206.212

Jana, S. and G. S. Shekhawat. 2010. Plant growth regulators, adenine sulfate and carbohydrates regulate organogenesis and in vitro flowering of Anethum graveolens. Acta Physiologiae Plantarum 33:305-311. doi: 10.1007/s11738-010-0548-0

Khan, M. A., and D. Pradhan. 2012. Antiurolithc activity of Ceropegia bulbosa extract in rats. Der Pharmacia Sinica 3(1): 148-152.

Mabberley, D. J. 1978. The plant book. Cambridge University Press, Cambridge.

Mathur, S., and G. S. Shekhawat. 2013. Establishment and characterization of Stevia rebaudiana (Bertoni) cell suspension culture: an in vitro approach for production of Steviosides. Acta Physiologiae Plantarum 35(3): $931-939$ doi: 10.1007/s11738-012-1136-2

Murashige, T., and F. Skoog. 1962. A revised medium for rapid growth and bioassays with tobacco tissue cultures. Acta Physiol Plant 15: 473-497. doi: 10.1111/j.1399-3054.1962.tb08052.x

Nadkarni, K. M. 1976. Indian Materia Medica. Popular Prakashan, Bombay, India, 303-304

Patel, A. K., M. Phulwaria, M. K. Rai, A. K. Gupta, S. Shekhawat, and N. S. Shekhawat. 2014. In vitro propagation and ex vitro rooting of Caralluma edulis (Edgew.) Benth. \& Hook. f.: an endemic and endangered edible plant species of the Thar Desert. Sci Hortic. 165:175-180. doi: 10.1016/j.scienta.2013.10.039

Phulwaria, M., N. S. Shekhawat, J. S. Rathore, and R. P. Singh. 2013. An efficient in vitro regeneration and ex vitro rooting of Ceropegia bulbosa Roxb.-A threatened and pharmaceutical important plant of Indian Thar Desert. Ind Crops Prod. 42: 2529. doi: 10.1016/j.indcrop.2012.05.013

Shekhawat, G. S., A. Batra, and S. Mathur. 2002. A reliable in vitro protocol for rapid mass propagation of Azadirachta indica Juss. Journal of Plant Biology 29(1): 109-112

Shekhawat, G. S., S. Mathur, and A. Batra. 2009. Role of phytohormones and various nitrogen inorganic and organic nutrients in induction of somatic embryogenesis in cell culture derived from leaflets of Azadirachta indica A. Juss. Biologia Plantarum 53 (4): 707-710. doi 10.1007/s10535-009-0127-7

Shekhawat, M. S., and N. S. Shekhawat. 2011. Micropropagation of Arnebia hispidissima (Lehm). DC. and production of alkannin from callus and cell suspension culture. Acta Physiol Plant. 33: 1445-1450. doi: 10.1007/s11738-010-0680-x

Singh, M., M. S. Rathore, D. Panwar, J. S. Rathore, H. R. Dagla, and N. S. Shekhawat. 2009 Micropropagation of selected genotype of Aloe vera L.-ancient plant for modern industry. J. Sustain. Forest. 28: 935-950. doi: 10.1080/10549810903344660

Singh, S. K., M. K. Rai, and L. Sahoo. 2012. An improved and efficient micropropagation of Eclipta alba through transverse thin cell layer culture and assessment of clonal fidelity using RAPD analysis. Industrial Crops and Products 37: 328-333. doi: 10.1016/j.indcrop.2011.12.005

Sukumar, E., G. R. Hamsaveni, and R. R. Bhima. 1996. Pharmacological actions of cerpegin, a novel pyridine alkaloid from Ceropegia juncea. Fitoterapia 66: 403-406

Swarnkar, S. and S. S., Katewa. 2008. Ethnobotanical observation on tuberous plants from tribal area of Rajasthan (India). Ethnobotanical Leaflets 12, 647-666.

Thiyagarajan, M. and P. Venkatachalam. 2012. Large scale in vitro propagation of Stevia rebaudiana (bert) for commercial application: pharmaceutically important and antidiabetic medicinal herb. Industrial Crops and Products 37: 111-117. doi: 10.1016/j.indcrop.2011.10.037

Wang, J., W. Gao, L. Zhang, and L. Huang. 2013. Establishment and quality assessment of tissue cultures in Glycyrrhiza uralensis Fisch. Appl Biochem Biotechnol. 169: 588-594. doi: 10.1007/s12010-012-0012-2

Walter, S. K. and J. Gillet. 1998. 1997 IUCN Red list of threatened plants. World Conservation Monitring Centre, Cambridge, UK

Yan, H. C., Liang, L. and Li. Y., Yang. 2010. In vitro and ex vitro rooting of Siratia grosvenorii, a traditional medicinal plant. Acta Physiol Plant. 32:115-120. doi: 10.1007/s11738-009-0386-0. 